\title{
Public Knowledge of Heart Attack in a Population Survey in Nepal
}

\author{
Yuba R. Limbu, Rabi Malin, Shyam R. Regmi, Ramesh Dahal, Hari L. \\ Nakarmi Ganesh Yonzan, Ritu P. Gartaula
}

Limited knowledge of heart attack symptoms causes patients' delay for early time Dependant thrombolytic therapy, which offers impressive survival benefit. Previous studies carried out in developed countries demonstrated the deficient of knowledge about wide range of heart attack symptoms. This study first reveals public awareness and knowledge of heart attack symptoms in developing country Like Nepal,

\section{Methods:}

Total 1192 participants (657 men, 535 women), age ranged from 16 to 88 years were interviewed. A standard questionnaire was administered to all participants in randomized cross sectional manner; Below 16 years of age, all health workers and individual with history of heart attack were excluded from the study.

\section{Results:}

Total $862(72.3 \%)$ respondents have heard heart attack, Signilicantly higher male participants have heard heart attack then female participants $(P<0.001)$. 91.7\% respondents with educational attainment of $\geq$ class 10 have heard heart attack while only $54 \%$ respondents with educational attainment <class 10 or illiterate have heard and in both male and female population higher percentage have heard in $\geq$ class 10 group then <class 10 or illiterate group (92.6\% Vs $60 \%$ and $85.6 \%$ Vs $49.6 \%)$, Significantly higher number of 31 to 50 years age group respondents have heard heart attack then 16 to 30 and $>50$ years age group $(P<0.001)$, Among 862 respondents $21.3 \%$ could not say any heart attack symptoms. Total 16 different heart attack symptoms were said, Faint/collapse $\left(48^{\circ} \%\right)$, chest pain $(22.4 \%)$, shortness of breath $(9 \%)$, dizziness $(8.4 \%)$, palpitation (7.4\%) and sweating (7.4\%) were leading symptoms said by respondents. Faint/collapse was said more frequently among ${ }^{3}$ class 10 attender 31 to 50 years age group males while chest pain and shortness of breath was said more frequently among $\geq$ class 10 attender $>50$ years age group males. Only $3.7 \%$ could say $\geq 2$ typical heart attack symptoms and significantly large number of $\geq$ class 10 group said $\geq 2$ typical heart attack symptoms then 
their counterparts $(P<0.001)$, Large number $(77.6 \%)$ of respondents prefer immediate hospital referral/doctor consultation after heart attack, Conclusion: 31 to 50 years age group literate males are more aware of heart attack. Faint/collapse, chest pain and shortness of breath are leading heart attack symptoms said by general population. Public heart attack awareness is not sufficient and knowledge of wide range of heart attack symptoms is deficient in general population. 